\title{
Associations between alcohol intake and diabetic retinopathy risk: a systematic review and meta-analysis
}

\author{
Chen Chen ${ }^{1,2}$, Zhaojun Sun ${ }^{2}$, Weigang $\mathrm{Xu}^{2}$, Jun Tan², Dan $\mathrm{Li}^{2}$, Yiting $\mathrm{Wu}^{2}$, Ting Zheng ${ }^{2}$ and Derong Peng ${ }^{2 *}$
}

\begin{abstract}
Background: Some previous studies have reported inconsistent results on the association between alcohol intake and diabetic retinopathy (DR) risk. This study aimed to evaluate the potential effects of alcohol intake on subsequent DR risk using a meta-analytic approach.

Methods: Three electronic databases (PubMed, EmBase, and the Cochrane library) were systematically searched for observational studies from their inception till November 2019. The pooled odds ratio (OR) with 95\% confidence interval (CI) were applied for the summary effect estimate using a random-effects model.

Results: A total of 15 studies (5 cohort studies, 4 case-control studies, and 6 cross-sectional studies) with 37,290 participants and 12,711 DR cases were selected for the final meta-analysis. The pooled OR indicated no significant association between alcohol intake and DR risk (OR: 0.91; 95\%Cl: 0.78-1.06; $P=0.225$ ), irrespective of the studies being pooled cohort (OR: 0.95; 95\%Cl: 0.66-1.36; $P=0.761)$, case-control (OR: 0.97; 95\%Cl: 0.77-1.23; $P=0.818)$, or cross-sectional (OR: $0.86 ; 95 \% \mathrm{Cl}: 0.69-1.08 ; P=0.190$ ) ones. However, this association might have been affected by the type of diabetes mellitus and the adjusted status.

Conclusion: The results of this study showed that the potential impact of alcohol intake on DR risk may differ according to the type of diabetes mellitus and adjusted status. Further large-scale, prospective cohort studies should be conducted to verify the findings of this study and to evaluate DR risk in relation to the dose and type of alcohol intake.
\end{abstract}

Keywords: Alcohol, Diabetic retinopathy, Meta-analysis

\section{Background}

Globally, diabetes mellitus (DM) has been rapidly increasing and is estimated to have affected about 422 million people and caused 1.6 million deaths in 2014 [1]. Diabetic patients experience progressive changes in their metabolic and inflammatory indices and several inflammatory markers [2-4]. Microvascular abnormalities and eye-related complications are most common in DM

\footnotetext{
*Correspondence: cc13916627775@163.com

${ }^{2}$ Shanghai Jing 'an District Pengpuxincun Community Health Service Center, No.15 Pingshun Road, Jing 'an District, Shanghai 200435, China

Full list of author information is available at the end of the article
}

patients [5, 6]. Diabetic retinopathy (DR) is one of the most severe complications of DM and accounts for nearly $40 \%$ of DM complications in patients aged $\geq 40$ years. Patients with DR have an increased risk of permanent visual impairment, and their quality of life is adversely affected [7-9]. A study reported that the prevalence of DR exceeds $75 \%$ in patients with DM for more than 20 years [10]. DR is the leading cause of impaired vision and blindness in DM patients and accounts for $4.8 \%$ of blindness cases worldwide [11, 12]. Therefore, identifying potential risk factors for the progression of DR is important in DM patients. 
Several studies have identified some of the potential risk factors for the progression of DR. A meta-analysis conducted by Song et al. contained 31 studies and found that insulin treatment, elevated fasting blood glucose levels, and high glycosylated hemoglobin concentrations are associated with an increased risk of DR in Chinese diabetic patients [13]. Moreover, several other risk factors, including hyperhomocysteinemia [14], vitamin D deficiency [15], obstructive sleep apnea [16], and obesity [17] have been demonstrated to be associated with an increased risk of DR. The investigating the potential role of alcohol intake on the risk of DR with an important public health implications owing to alcohol was the most widely consumed beverages. Therefore, to clarify the role of alcohol intake plays in DR is particularly important, as it not defined in general and DM populations. In this study, we attempted a large-scale examination of the available observational studies to determine the association between alcohol intake and DR risk. Stratified analyses were also conducted according to the study design.

\section{Methods}

Data sources, search strategy, and selection criteria

This review was conducted and reported according to the Preferred Reporting Items for Systematic Reviews and Meta-Analysis Statement issued in 2009 [18]. Observational studies that investigated the association of alcohol intake with DR were included in this study, without restrictions on language and published status. Three electronic databases PubMed, EmBase, and the Cochrane library were systematically searched throughout November 2019 using "alcohol" and "diabetic retinopathy" as the core search terms. Manual searches were also performed for the reference lists of the retrieved studies to identify any new eligible study.

A standardized approach was applied by two of the authors for the literature search and study selection, with any disagreement between them resolved by a group discussion until a consensus was reached. The inclusion criteria of this study were as follows: (1) Study design: observational studies, including cohort, case-control, and cross-sectional studies; (2) Participants: there were no restrictions, with the inclusion of general population as well type $1 \mathrm{DM}$, type $2 \mathrm{DM}$, or mixed patients; (3) Exposure: alcohol intake; and (4) Outcomes: studies reporting an effect estimate and 95\% confidence intervals (CIs) for comparisons of high and low alcohol intake on the risk of DR. The maximally adjusted results were selected if the study reported several adjusted effect estimates.

\section{Data collection and quality assessment}

Data collection and quality assessment were performed by two authors, and any inconsistency was settled by an additional author by referring to the original article. The following data items were collected: first author's surname, publication year, study design, country, sample size, male participant percentage, mean age, number of cases, DR diagnosis, DR definition, population status, exposure definition, effect estimate and its $95 \% \mathrm{CI}$, and covariates in the fully adjusted model. The quality of identified studies was assessed using Newcastle-Ottawa Scale (NOS), which has already been partially validated for assessing the quality of observational studies in meta-analyses [19]. NOS comprises a star system that includes selection (four items), comparability (one item), and outcome (three items) categories; the number of stars awarded ranges from 0 to 9 .

\section{Statistical analysis}

The association between alcohol intake and DR risk on the basis of effect estimate and corresponding 95\%CIs in each study as well as the pooled odds ratio (OR) with $95 \% \mathrm{CI}$ was calculated using the random-effects model [20, 21]. $I^{2}$ index and Q statistic was applied to assess heterogeneity among the studies, and $I^{2}>50.0 \%$ or $P<$ 0.10 was considered as significant heterogeneity $[22,23]$. The robustness of pooled conclusion was evaluated using a sensitivity analysis [24]. Subgroup analyses were also conducted based on countries, publication year, population status, adjusted status, and study quality according to the study design. The $P$ value between the subgroups was assessed using an interaction test [25]. Publication bias was assessed using the funnel plot and Egger's and Begg's tests [26, 27]. All reported $P$ values are two-sided, and $\mathrm{P}$ values $<0.05$ were considered significant for all the included studies. Statistical analyses were performed using STATA software (version 12.0; Stata Corporation, College Station, TX, USA).

\section{Results}

Literature search

A total of 483 articles were identified in our initial electronic searches; 460 studies were excluded due to duplication and irrelevancy. A total of 23 potentially eligible studies were selected for further full-text evaluations, and 8 studies were excluded due to other disease status $(n=2)$, other exposure $(n=3)$, and the study being a review or meta-analysis $(\mathrm{n}=3)$. Eventually, 15 observational studies were selected for the final quantitative analysis [28-42]. A manual search for the reference lists yielded two studies, and these two studies were included in the initial electronic searches. Figure 1 presents the study selection process; the baseline characteristics of the included studies and participants are summarized in Table 1.

\section{Study characteristics}

Of the 15 included studies, 5 were cohort, 4 were casecontrol, and the remaining 6 were cross-sectional 


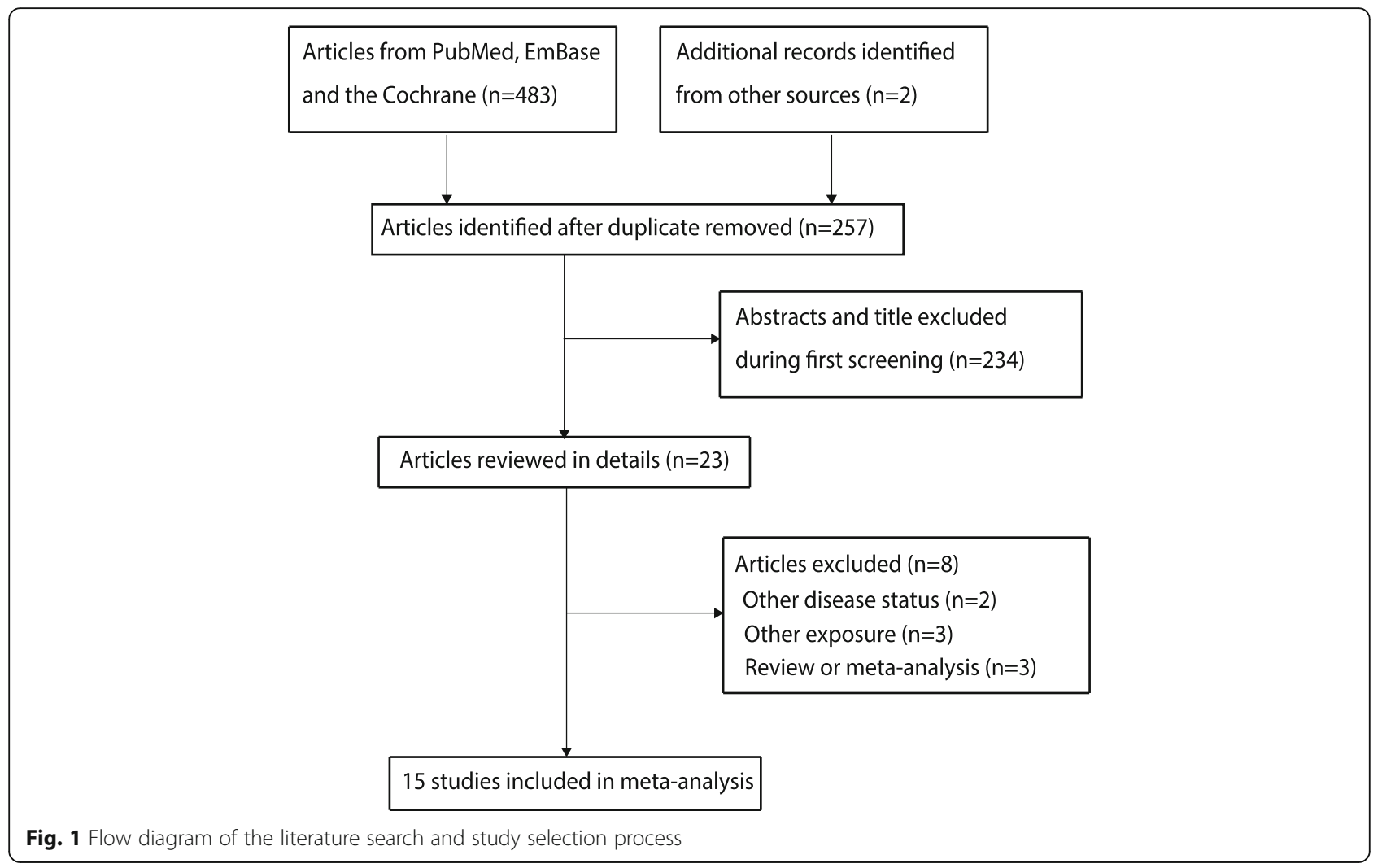

studies. The studies were published between 1984 and 2016, and the participants in the individual studies ranges from 132 to 17,130 . A total of 11 studies were conducted in Western countries, and the remaining 4 studies were conducted in Eastern countries. Three studies included type $1 \mathrm{DM}$ patients, seven included type 2 DM patients, four included both type 1 and type $2 \mathrm{DM}$ patients, and the remaining study included the general population. Nine studies reported that effect estimates were adjusted for potential covariates, and the remaining six studies reported crude effect estimates. Studies were assessed using NOS: two studies were awarded 8 stars, three studies were awarded 7 stars, seven studies were awarded 6 stars, one study was awarded 5 stars, 1 study was awarded 4 stars, and the remaining study was awarded 3 stars.

\section{Meta-analysis}

After pooling all the included studies, the pooled OR indicated no significant association between alcohol intake and DR risk (OR: 0.91; 95\%CI: $0.78-1.06 ; P=0.225$; Fig. 2), and significant heterogeneity was observed across the studies $\left(I^{2}=62.8 \% ; P=0.001\right)$. The conclusion was not altered by sequentially excluding individual studies (Fig. 3). When stratified by study design, no significant associations were observed irrespective of the studies being pooled cohort (OR: $0.95 ; 95 \% \mathrm{CI}$ : $0.66-1.36 ; P=$
0.761), case-control (OR: $0.97 ; 95 \%$ CI: $0.77-1.23 ; P=$ 0.818 ), or cross-sectional (OR: 0.86 ; $95 \% \mathrm{CI}$ : $0.69-1.08$; $P=0.190$ ) ones. Sensitivity analyses were also conducted according to the study design, showing that alcohol intake was not associated with DR risk in cohort and cross-sectional studies, whereas a potential significant association was observed in case-control studies (Additional file 1, Additional file 2 and Additional file 3).

\section{Subgroup analysis}

Subgroup analyses were conducted to evaluate the association between alcohol intake and DR risk according to the study design (Table 2). When stratified analyses were conducted for cohort studies, alcohol intake was found to be associated with a reduced DR risk if the study included general population; furthermore, the association between alcohol intake and DR risk could be affected by the adjusted status and study quality. When stratified analyses were conducted for case-control studies, alcohol intake was found to be associated with an increased DR risk if the analysis included pooled studies published in or after 2010, studies on type 2 DM patients, studies reporting adjusted effect estimates, and studies with high quality; however, alcohol intake was associated with a reduced DR risk if studies included both type 1 and type 2 DM patients. Moreover, the association of alcohol intake with DR risk could be affected by the population status. 


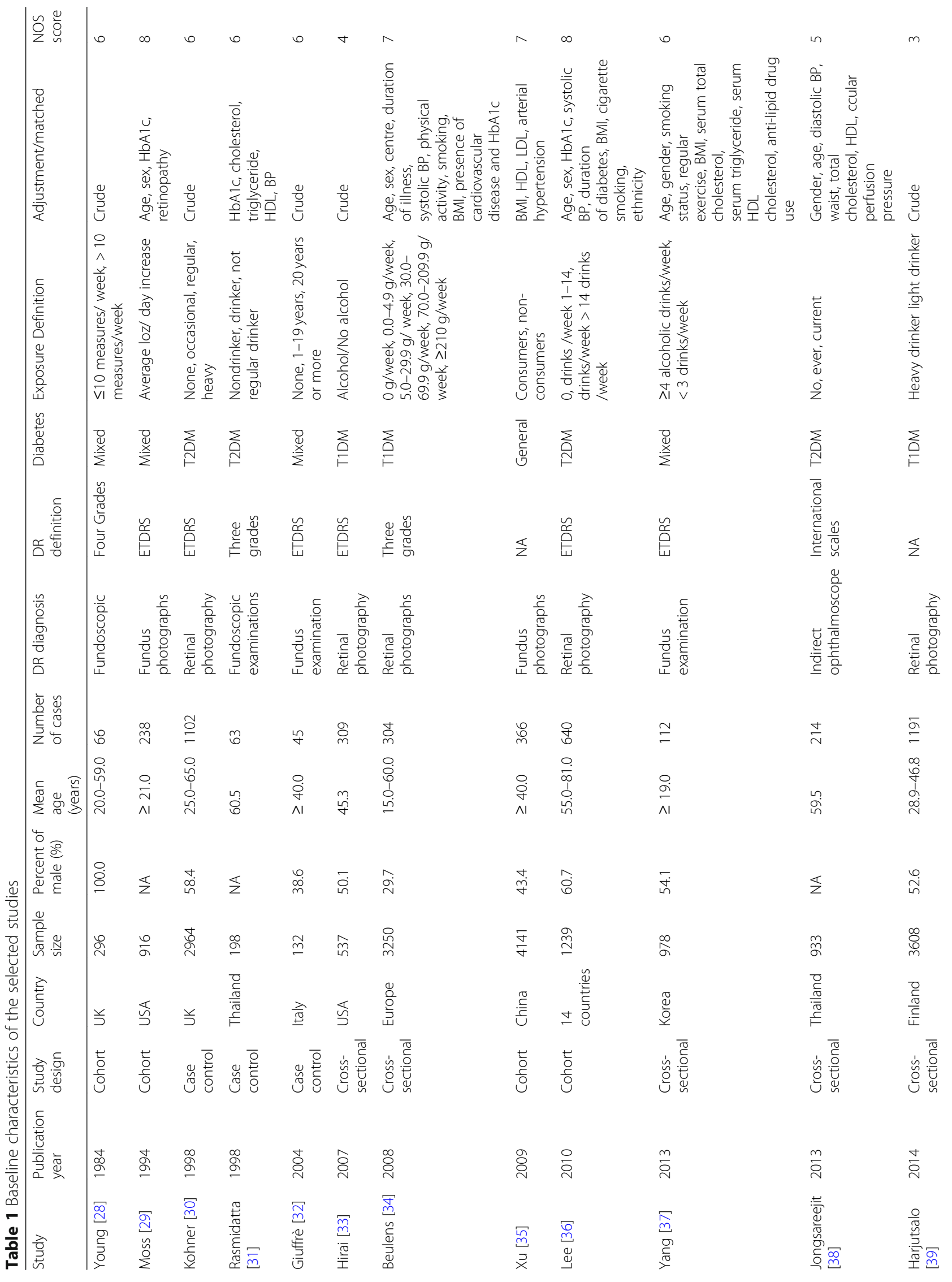


Chen et al. BMC Endocrine Disorders $\quad$ (2020) 20:106

Page 5 of 10

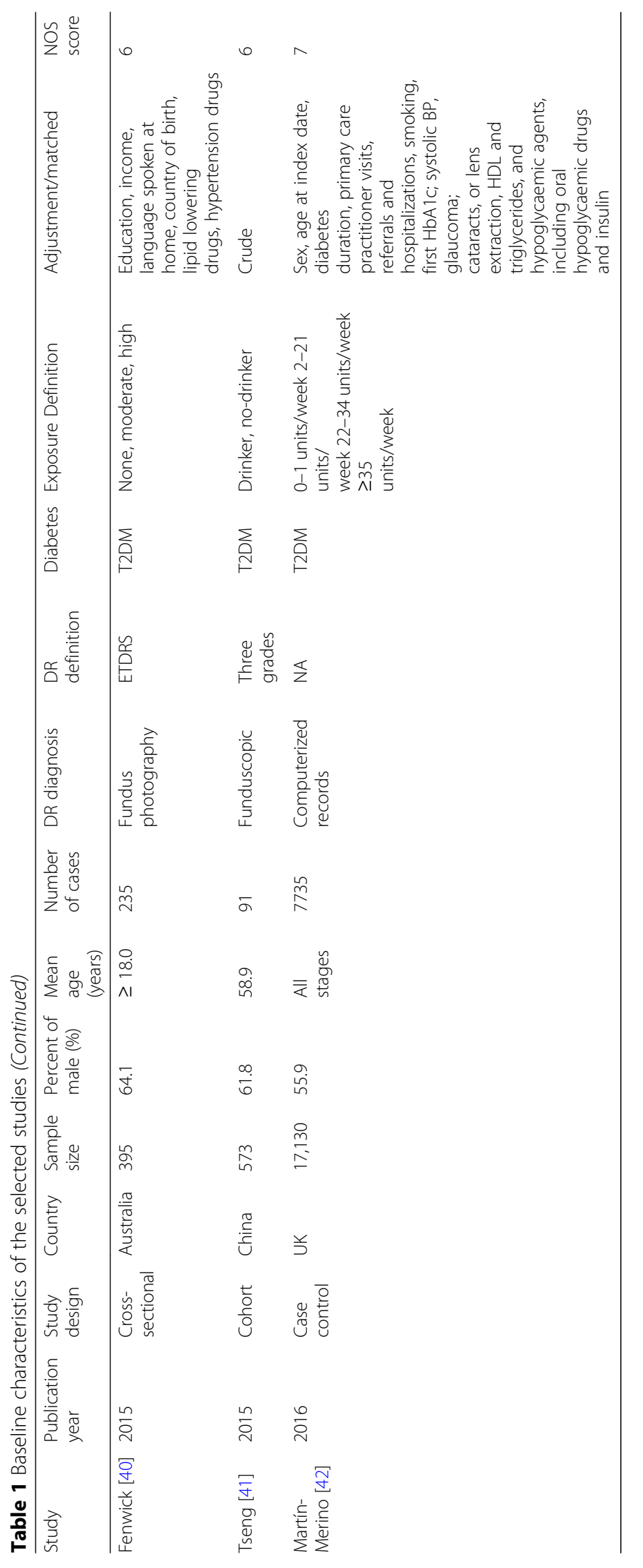




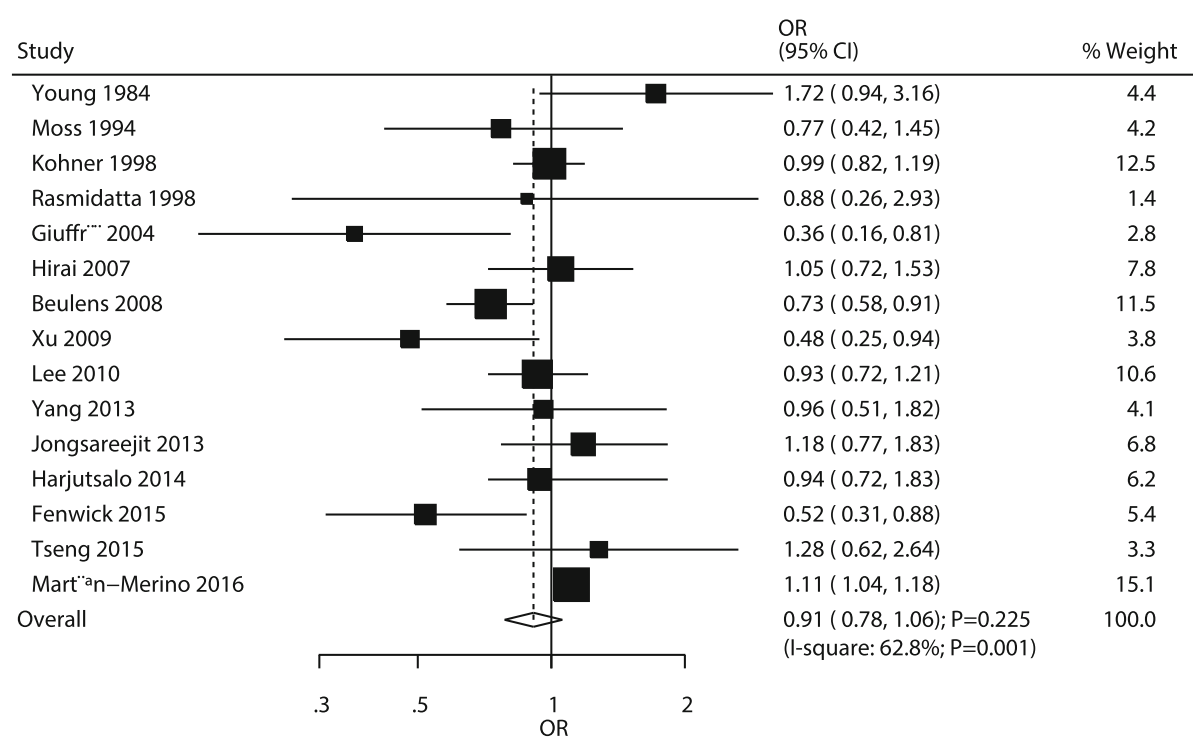

Fig. 2 The pooled odds ratio for the association of alcohol intake with diabetic retinopathy risk

When stratified analyses were conducted for crosssectional studies, alcohol intake was found to be associated with a reduced DR risk if the pooled studies were of high quality.

\section{Publication bias}

The publication bias could not be ruled out by reviewing the funnel plot for the association between alcohol intake and DR risk (Fig. 4). Although the Begg's test indicated no significant publication bias $(P=0.692)$, the Egger's test suggested significant publication bias $(P=0.044)$. The conclusions were unaltered after adjustments for publication bias through the trim and fill method [43].

\section{Discussion}

This study was conducted on the basis of previously published observational studies, and it evaluated the

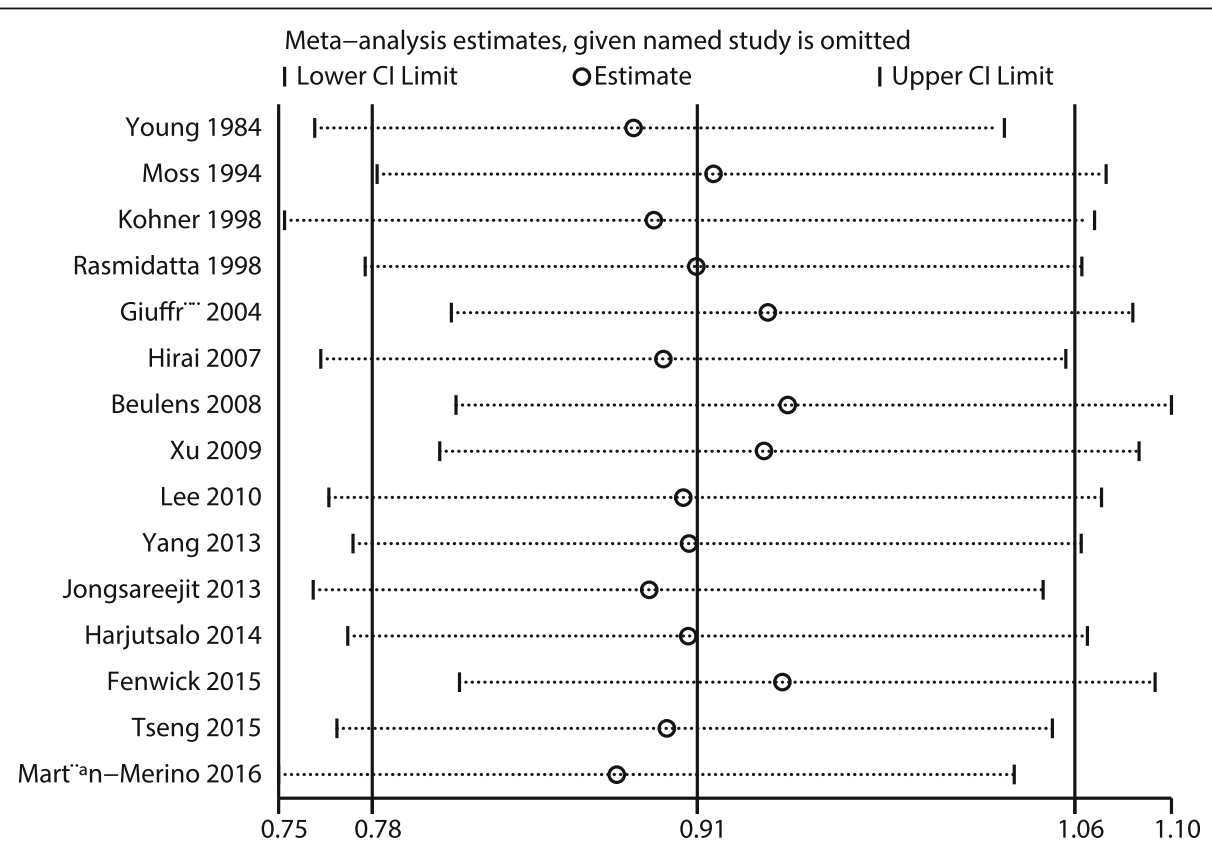

Fig. 3 Sensitivity analysis 
Table 2 Subgroup analyses according to study design

\begin{tabular}{|c|c|c|c|c|c|c|c|}
\hline Study design & Factors & Group & OR and $95 \% \mathrm{Cl}$ & $P$ value & $\begin{array}{l}\text { Heterogeneity } \\
(\%)\end{array}$ & $\begin{array}{l}P \text { value } \\
\text { for } Q \text { test }\end{array}$ & $\begin{array}{l}\text { P value betweer } \\
\text { subgroups }\end{array}$ \\
\hline \multirow[t]{11}{*}{ Cohort studies } & \multirow[t]{2}{*}{ Countries } & Western & $1.04(0.70-1.53)$ & 0.855 & 50.5 & 0132 & 0.318 \\
\hline & & Eastern & $0.77(0.30-2.03)$ & 0.603 & 73.9 & 0.050 & \\
\hline & \multirow[t]{2}{*}{ Publication year } & Before 2010 & $0.87(0.42-1.80)$ & 0.703 & 75.3 & 0.018 & 0.722 \\
\hline & & 2010 or after & $0.96(0.76-1.23)$ & 0.771 & 0.0 & 0.416 & \\
\hline & \multirow[t]{3}{*}{ Population } & T2DM & $0.96(0.76-1.23)$ & 0.771 & 0.0 & 0.416 & 0.086 \\
\hline & & Mixed & $1.15(0.52-2.54)$ & 0.722 & 69.7 & 0.069 & \\
\hline & & General & $0.48(0.25-0.93)$ & 0.030 & - & - & \\
\hline & \multirow[t]{2}{*}{ Adjusted status } & Yes & $0.77(0.53-1.11)$ & 0.162 & 41.3 & 0.182 & 0.024 \\
\hline & & No & $1.52(0.96-2.42)$ & 0.076 & 0.0 & 0.540 & \\
\hline & \multirow[t]{2}{*}{ Study quality } & High & $0.77(0.53-1.11)$ & 0.162 & 41.3 & 0.182 & 0.024 \\
\hline & & Low & $1.52(0.96-2.42)$ & 0.076 & 0.0 & 0.540 & \\
\hline \multirow[t]{10}{*}{ Case control studies } & \multirow[t]{2}{*}{ Countries } & Western & $0.97(0.75-1.24)$ & 0.792 & 76.5 & 0.014 & 0.729 \\
\hline & & Eastern & $0.88(0.26-2.95)$ & 0.836 & - & - & \\
\hline & \multirow[t]{2}{*}{ Publication year } & Before 2010 & $0.71(0.36-1.41)$ & 0.332 & 64.9 & 0.058 & 0.086 \\
\hline & & 2010 or after & $1.11(1.04-1.18)$ & 0.001 & - & - & \\
\hline & \multirow[t]{2}{*}{ Population } & $\mathrm{T} 2 \mathrm{DM}$ & $1.10(1.03-1.16)$ & 0.003 & 0.0 & 0.490 & 0.007 \\
\hline & & Mixed & $0.36(0.16-0.81)$ & 0.014 & - & - & \\
\hline & \multirow[t]{2}{*}{ Adjusted status } & Yes & $1.11(1.04-1.18)$ & 0.001 & 0.0 & 0.707 & 0.093 \\
\hline & & No & $0.65(0.24-1.72)$ & 0.383 & 82.4 & 0.017 & \\
\hline & \multirow[t]{2}{*}{ Study quality } & High & $1.11(1.04-1.18)$ & 0.001 & - & - & 0.086 \\
\hline & & Low & $0.71(0.36-1.41)$ & 0.332 & 64.9 & 0.058 & \\
\hline \multirow[t]{11}{*}{ Cross-sectional studies } & \multirow[t]{2}{*}{ Countries } & Western & $0.79(0.61-1.03)$ & 0.080 & 46.9 & 0.130 & 0.088 \\
\hline & & Eastern & $1.11(0.77-1.58)$ & 0.583 & 0.0 & 0.599 & \\
\hline & \multirow[t]{2}{*}{ Publication year } & Before 2010 & $0.85(0.60-1.20)$ & 0.354 & 62.0 & 0.105 & 0.532 \\
\hline & & 2010 or after & $0.87(0.61-1.24)$ & 0.451 & 48.4 & 0.121 & \\
\hline & \multirow[t]{3}{*}{ Population } & T1DM & $0.85(0.67-1.08)$ & 0.187 & 33.5 & 0.223 & 0.896 \\
\hline & & T2DM & $0.79(0.36-1.77)$ & 0.573 & 82.2 & 0.018 & \\
\hline & & Mixed & $0.96(0.51-1.81)$ & 0.900 & - & - & \\
\hline & \multirow[t]{2}{*}{ Adjusted status } & Yes & $0.80(0.59-1.10)$ & 0.170 & 54.4 & 0.087 & 0.144 \\
\hline & & No & $1.01(0.75-1.35)$ & 0.973 & 00 & 0.718 & \\
\hline & \multirow[t]{2}{*}{ Study quality } & High & $0.73(0.58-0.91)$ & 0.006 & - & - & 0.114 \\
\hline & & Low & $0.92(0.70-1.20)$ & 0.538 & 36.9 & 0.175 & \\
\hline
\end{tabular}

association of alcohol intake with DR risk. This quantitative meta-analysis included 37,290 participants and 12,711 DR cases from 5 cohort studies, 4 casecontrol studies, and 6 cross-sectional studies across a wide range of participant characteristics. The findings of this study show no significant association between alcohol intake and DR risk, irrespective of the studies being pooled cohort, case-control, or cross-sectional ones. Sensitivity analysis suggested potential beneficial effects of alcohol intake on DR risk in case-control studies. Finally, the association of alcohol intake with DR risk according to study design varied when the studies were stratified by countries, publication year, population status, adjusted status, and quality.

A meta-analysis conducted by Zhu et al. included a total of 15 studies and found that alcohol intake was not associated with DR risk. Interestingly, wine or sherry intake was associated with a reduced DR risk [44]. They attributed the results to the potential protective effects of low to moderate alcohol intake on the risk of DM and cardiovascular disease $[45,46]$. However, the inflammatory response and oxidative stress could be affected by alcohol and are significantly associated with DR risk [47, 48]. The stratified analyses from the previous meta- 
Funnel plot with pseudo 95\% confidence limits

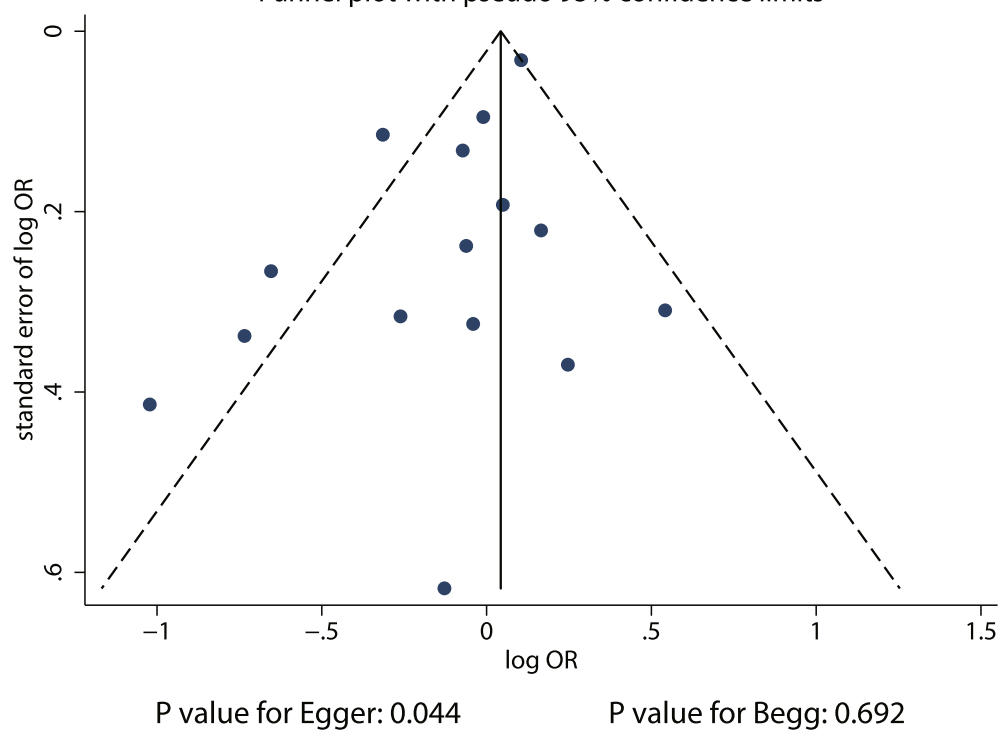

Fig. 4 Publication bias

analysis were mixed owing to, studies with various designs, and the results of such stratified analyses are unreliable. Therefore, the present study may correct the inappropriate results reported by such stratified analyses.

Although no significant association between alcohol intake and DR risk was observed in most of the studies included in our meta-analysis, many of these studies reported inconsistent results. The Casteldaccia Eye Study found that the duration of alcohol intake between 1 and 19 years was not associated with DR risk, whereas alcohol intake for $\geq 20$ years was associated with a reduced DR risk [32]. Beulens et al. reported that moderate alcohol intake was associated with a reduced risk of microvascular complications among type $1 \mathrm{DM}$ patients [34]. The Beijing Eye Study suggested that alcohol intake was associated with a reduced DR risk in general population [35]. A study conducted by Fenwick et al. found that moderate white and fortified wine intake was correlated with DR risk among type 2 DM patients [40]. They pointed out the beneficial effects induced by alcohol intake due to increase in high-density lipoprotein levels, reduction in platelet aggregation, and decrease in fibrinogen levels [49]. However, a case-control study in a UK primary care setting indicated that alcohol intake was associated with an increased DR risk among type 2 DM patients [42]. A possible reason for this could be the moderate to heavy rate at which alcohol was consumed by the participants of that study, which has been associated with an increased DR risk.

The results of the subgroup analyses showed that the association of alcohol intake with DR risk is multifaceted when stratified by countries, publication year, population status, adjusted status, and study quality. First, we found that the association of alcohol intake with DR risk persisted even after stratification by countries, irrespective of the studies being cohort, case-control, or crosssectional ones. However, the heterogeneity remained and was not fully explained. Second, we found that alcohol intake was associated with an increased DR risk in studies published in or after 2010 when stratified by case-control cohorts; this result was obtained from only one study and has been previously identified [42]. Third, we found that alcohol intake was associated with an increased DR risk if only type 2 DM patients were included, whereas the risk was significantly reduced if both type 1 and type $2 \mathrm{DM}$ patients were included in stratified case-control cohorts. This could be due to the study conducted by Martín-Merino et al. contributing a large weight to the overall analysis [42]. A similar result was observed when the studies were stratified by adjusted status. Finally, when the studies were pooled by design as case-control or cross-sectional studies with high quality, conflicting results were observed. However, this observation was obtained from only one study, and the conclusions were not reliable.

There are several limitations to this study. First, most of the included studies (10/15) were designed as casecontrol or cross-sectional studies, making it difficult to distinguish cause-and-effect relationships. Second, the drinking habits and other lifestyle factors after the diagnosis of DM may have changed, altering the effects of alcohol intake on DR risk and biasing the results. Third, the adjusted status and included covariates were different across the included studies, which could affect the 
reliability of the pooled conclusion. Forth, stratified analyses according to sex, the dose and type of alcohol intake were not conducted owing to mostly included studies did not report these data. Finally, the inherent limitations of traditional meta-analysis, including publication bias and study level-based analysis, affect the reliability of conclusion and restrict the results of detailed analyses.

\section{Conclusions}

In conclusion, the findings of this study suggest no significant association between alcohol intake and DR risk. Moreover, this lack of association might have been affected by population status, adjusted status, and study quality. This association should be verified in further large-scale, prospective studies, and DR risk in relation to the dose and type of alcohol intake should also be explored.

\section{Supplementary information}

Supplementary information accompanies this paper at https://doi.org/10. 1186/s12902-020-00588-3.

Additional file 1. Sensitivity for cohort studies.

Additional file 2. Sensitivity for case control studies.

Additional file $\mathbf{3}$. Sensitivity for cross-section studies.

\section{Abbreviations}

DR: Diabetic retinopathy; OR: Odds ratio; Cl: Confidence interval;

DM: Diabetes mellitus; NOS: Newcastle-Ottawa Scale

\section{Acknowledgements}

Not applicable

\section{Authors' contributions}

CC and DRP developed the concept of this study; WGX and ZJS did the literature research and data analysis; DL, JT, YTW and TZ contributed to the experimental technique; CC drafted the manuscript. All authors have read and approved the final manuscript.

\section{Funding}

The design of this study and statistics was funded by Experimental study on the management mode of berberine combined with family doctors to delay retinopathy in community type II diabetic patients (Community 2018SQ05), and Intervention study of berberine combined with comprehensive treatment for type II diabetic retinopathy in north Shanghai community (TYS2018M008).

\section{Availability of data and materials}

The datasets used and/or analysed during the current study are available from the corresponding author on reasonable request.

\section{Ethics approval and consent to participate}

Not applicable.

\section{Consent for publication}

Not applicable.

\section{Competing interests}

The authors declare that they have no competing interests.

\section{Author details}

${ }^{1}$ Shanghai Jing 'an District Jiangning Road Community Health Service Center, Shanghai, China. ${ }^{2}$ Shanghai Jing 'an District Pengpuxincun Community Health Service Center, No.15 Pingshun Road, Jing 'an District, Shanghai 200435, China.

Received: 13 February 2020 Accepted: 7 July 2020

Published online: 17 July 2020

\section{References}

1. World Health Organization: Global report on diabetes. http://apps.who.int/ iris/bitstream/10665/204871/1/9789241565257_eng.pdf?ua=1. Accessed Nov 2019.

2. Dain A, Repossi G, Das UN, Eynard AR. Role of PUFAs, the precursors of endocannabinoids, in human obesity and type 2 diabetes. Front Biosci (Elite Ed). 2010;2:1432-47.

3. Dain A, Repossi G, Diaz-Gerevini GT, Vanamala J, Das UN, Eynard AR. Long chain polyunsaturated fatty acids (LCPUFAs) and nordihydroguaiaretic acid (NDGA) modulate metabolic and inflammatory markers in a spontaneous type 2 diabetes mellitus model (Stillman Salgado rats). Lipids Health Dis. 2016;15(1):205.

4. Grosick R, Alvarado-Vazquez PA, Messersmith AR, Romero-Sandoval EA. High glucose induces a priming effect in macrophages and exacerbates the production of pro-inflammatory cytokines after a challenge. J Pain Res. 2018;11:1769-78.

5. Zoungas S, Woodward M, Li Q, Cooper ME, Hamet P, Harrap S, Heller S, Marre M, Patel A, Poulter $\mathrm{N}$, et al. Impact of age, age at diagnosis and duration of diabetes on the risk of macrovascular and microvascular complications and death in type 2 diabetes. Diabetologia. 2014;57(12): 2465-74.

6. Association AD. Diagnosis and classification of diabetes mellitus. Diabetes Care. 2010;33(Suppl 1):S62.

7. Kusuhara S, Fukushima Y, Ogura S, Inoue N, Uemura A. Pathophysiology of diabetic retinopathy: the old and the new. Diabetes Metab J. 2018;42(5): 364-76.

8. Sabanayagam C, Banu R, Chee ML, Lee R, Wang YX, Tan G, Jonas JB, Lamoureux EL, Cheng CY, Klein BEK, et al. Incidence and progression of diabetic retinopathy: a systematic review. Lancet Diabetes Endocrinol. 2019; 7(2):140-9.

9. Cheung N, Mitchell P, Wong TY. Diabetic retinopathy. Lancet (London, England). 2010;376(9735):124-36.

10. Barcelo A, Aedo C, Rajpathak S, Robles S. The cost of diabetes in Latin America and the Caribbean. Bull World Health Organ. 2003;81(1):19-27.

11. Kowluru RA. Mitochondria damage in the pathogenesis of diabetic retinopathy and in the metabolic memory associated with its continued progression. Curr Med Chem. 2013;20(26):3226-33.

12. Resnikoff S, Pascolini D, Etya'ale D, Kocur I, Pararajasegaram R, Pokharel GP, Mariotti SP. Global data on visual impairment in the year 2002. Bull World Health Organ. 2004;82(11):844-51.

13. Song $P, Y u$ J, Chan KY, Theodoratou E, Rudan I. Prevalence, risk factors and burden of diabetic retinopathy in China: a systematic review and metaanalysis. J Glob Health. 2018;8(1):010803.

14. Xu C, Wu Y, Liu G, Liu X, Wang F, Yu J. Relationship between homocysteine level and diabetic retinopathy: a systematic review and meta-analysis. Diagn Pathol. 2014:9:167

15. Luo BA, Gao F, Qin LL. The Association between Vitamin D Deficiency and Diabetic Retinopathy in Type 2 Diabetes: A Meta-Analysis of Observational Studies. Nutrients. 2017:9(3):307.

16. Zhu Z, Zhang F, Liu Y, Yang S, Li C, Niu Q, Niu J. Relationship of obstructive sleep Apnoea with diabetic retinopathy: a meta-analysis. Biomed Res Int. 2017;2017:4737064.

17. Zhu W, Wu Y, Meng YF, Xing Q, Tao JJ, Lu J. Association of obesity and risk of diabetic retinopathy in diabetes patients: a meta-analysis of prospective cohort studies. Medicine. 2018;97(32):e11807.

18. Moher D, Liberati A, Tetzlaff J, Altman DG. Preferred reporting items for systematic reviews and meta-analyses: the PRISMA statement. PLoS Med. 2009;6(7):e1000097.

19. Wells G, Shea B, O'Connell D, Peterson J, Welch V, Losos M, Tugwell P. The Newcastle-Ottawa Scale (NOS) for assessing the quality of nonrandomized studies in meta-analyses. 2009. Ottawa Hospital Research Institute web site. Ottawa: L'Hopital d'Ottawa Institut de Recherche; 2014. 
20. DerSimonian R, Laird N. Meta-analysis in clinical trials. Control Clin Trials. 1986;7(3):177-88.

21. Ades AE, Lu G, Higgins JP. The interpretation of random-effects metaanalysis in decision models. Med Decis Making. 2005;25(6):646-54.

22. Deeks JJ, Fellow JPHSSV, Altman DG. Analyzing data and undertaking metaanalyses. In: Higgins J, Green S, editors. Cochrane Handbook for Systematic Reviews of Interventions 501. Oxford: The Cochrane Collaboration; 2008.

23. Higgins JP, Thompson SG, Deeks JJ, Altman DG. Measuring inconsistency in meta-analyses. BMJ. 2003;327(7414):557-60.

24. Tobias A. Assessing the influence of a single study in the meta-analysis estimate. Stata Tech Bull. 1999:47:15-7.

25. Altman DG, Bland JM. Interaction revisited: the difference between two estimates. BMJ. 2003;326(7382):219.

26. Egger M, Davey Smith G, Schneider M, Minder C. Bias in meta-analysis detected by a simple, graphical test. BMJ. 1997;315(7109):629-34.

27. Begg CB, Mazumdar M. Operating characteristics of a rank correlation test for publication bias. Biometrics. 1994;50(4):1088-101.

28. Young RJ, McCulloch DK, Prescott RJ, Clarke BF. Alcohol: another risk factor for diabetic retinopathy? Br Med J (Clin Res Ed). 1984;288(6423):1035-7.

29. Moss SE, Klein R, Klein BE. The association of alcohol consumption with the incidence and progression of diabetic retinopathy. Ophthalmology. 1994; 101(12):1962-8.

30. Kohner EM, Aldington SJ, Stratton IM, Manley SE, Holman RR, Matthews DR, Turner RC. United Kingdom prospective diabetes study, 30: diabetic retinopathy at diagnosis of non-insulin-dependent diabetes mellitus and associated risk factors. Arch Ophthalmol. 1998;116(3):297-303.

31. Rasmidatta S, Khunsuk-Mengrai K, Warunyuwong C. Risk factors of diabetic retinopathy in non-insulin dependent diabetes mellitus. J Med Assoc Thail. 1998:81(3):169-74.

32. Giuffre $\mathrm{G}$, Lodato $\mathrm{G}$, Dardanoni $\mathrm{G}$. Prevalence and risk factors of diabetic retinopathy in adult and elderly subjects: the Casteldaccia eye study. Graefes Arch Clin Exp Ophthalmol. 2004;242(7):535-40.

33. Hirai FE, Moss SE, Klein BE, Klein R. Severe hypoglycemia and smoking in a long-term type 1 diabetic population: Wisconsin epidemiologic study of diabetic retinopathy. Diabetes Care. 2007;30(6):1437-41.

34. Beulens JW, Kruidhof JS, Grobbee DE, Chaturvedi N, Fuller JH, SoedamahMuthu SS. Alcohol consumption and risk of microvascular complications in type 1 diabetes patients: the EURODIAB prospective complications study. Diabetologia. 2008:51(9):1631-8.

35. Xu L, You QS, Jonas JB. Prevalence of alcohol consumption and risk of ocular diseases in a general population: the Beijing eye study. Ophthalmology. 2009;116(10):1872-9.

36. Lee CC, Stolk RP, Adler Al, Patel A, Chalmers J, Neal B, Poulter N, Harrap S, Woodward M, Marre M, et al. Association between alcohol consumption and diabetic retinopathy and visual acuity-the AdRem study. Diabet Med. 2010;27(10):1130-7.

37. Yang JY, Kim NK, Lee YJ, Noh JH, Kim DJ, Ko KS, Rhee BD, Kim DJ. Prevalence and factors associated with diabetic retinopathy in a Korean adult population: the 2008-2009 Korea National Health and nutrition examination survey. Diabetes Res Clin Pract. 2013;102(3):218-24.

38. Jongsareejit A, Potisat S, Krairittichai U, Sattaputh C, Arunratanachote W. The Thai DMS diabetes complications (DD.Comp.) project: prevalence and risk factors of diabetic retinopathy in Thai patients with type 2 diabetes mellitus. J Med Assoc Thail. 2013;96(11):1476-82.

39. Harjutsalo V, Feodoroff M, Forsblom C, Groop PH. Patients with type 1 diabetes consuming alcoholic spirits have an increased risk of microvascular complications. Diabet Med. 2014;31(2):156-64.

40. Fenwick EK, Xie J, Man RE, Lim LL, Flood VM, Finger RP, Wong TY, Lamoureux EL. Moderate consumption of white and fortified wine is associated with reduced odds of diabetic retinopathy. J Diabetes Complicat. 2015;29(8):1009-14.

41. Tseng ST, Chou ST, Low BH, Su FL. Risk factors associated with diabetic retinopathy onset and progression in diabetes patients: a Taiwanese cohort study. Int J Clin Exp Med. 2015;8(11):21507-15.

42. Martin-Merino E, Fortuny J, Rivero-Ferrer E, Lind M, Garcia-Rodriguez LA. Risk factors for diabetic retinopathy in people with type 2 diabetes: a case-control study in a UK primary care setting. Prim Care Diabetes. 2016;10(4):300-8.

43. Duval S, Tweedie R. A nonparametric "trim and fill" method of accounting for publication bias in meta-analysis. J Am Stat Assoc. 2000; 95(449):89-98
44. Zhu W, Meng YF, Wu Y, Xu M, Lu J. Association of alcohol intake with risk of diabetic retinopathy: a meta-analysis of observational studies. Sci Rep. 2017;7(1):4.

45. Raum P, Lamparter J, Ponto KA, Peto T, Hoehn R, Schulz A, Schneider A, Wild PS, Pfeiffer N, Mirshahi A. Prevalence and cardiovascular associations of diabetic retinopathy and Maculopathy: results from the Gutenberg health study. PLoS One. 2015;10(6):e0127188.

46. Li XH, Yu FF, Zhou YH, He J. Association between alcohol consumption and the risk of incident type 2 diabetes: a systematic review and dose-response meta-analysis. Am J Clin Nutr. 2016;103(3):818-29.

47. Yu W, Fu YC, Wang W. Cellular and molecular effects of resveratrol in health and disease. J Cell Biochem. 2012;113(3):752-9.

48. Srikanta AH, Kumar A, Sukhdeo SV, Peddha MS, Govindaswamy V. The antioxidant effect of mulberry and jamun fruit wines by ameliorating oxidative stress in streptozotocin-induced diabetic Wistar rats. Food Funct. 2016;7(10):4422-31.

49. MosS SE, Klein R, Klein BE. Alcohol consumption and the prevalence of diabetic retinopathy. Ophthalmology. 1992;99(6):926-32.

\section{Publisher's Note}

Springer Nature remains neutral with regard to jurisdictional claims in published maps and institutional affiliations.
Ready to submit your research? Choose BMC and benefit from:

- fast, convenient online submission

- thorough peer review by experienced researchers in your field

- rapid publication on acceptance

- support for research data, including large and complex data types

- gold Open Access which fosters wider collaboration and increased citations

- maximum visibility for your research: over $100 \mathrm{M}$ website views per year

At BMC, research is always in progress.

Learn more biomedcentral.com/submissions 